\title{
Rémy Boucharlat. « À propos de parayadām et paradis perse : perplexité de l'archéologue et perspectives »
}

\section{Astrid Nunn}

\section{(2) OpenEdition}

Journals

Édition électronique

URL : http://journals.openedition.org/abstractairanica/46193

DOI : 10.4000/abstractairanica.46193

ISBN : 1961-960X

ISSN : 1961-960X

Éditeur :

CNRS (UMR 7528 Mondes iraniens et indiens), Éditions de l'IFRI

\section{Référence électronique}

Astrid Nunn, « Rémy Boucharlat. «À propos de parayadām et paradis perse : perplexité de

l'archéologue et perspectives » », Abstracta Iranica [En ligne], Volume 37-38-39 | 2018, document 73, mis en ligne le 30 décembre 2018, consulté le 02 octobre 2020. URL : http://journals.openedition.org/ abstractairanica/46193 ; DOI : https://doi.org/10.4000/abstractairanica.46193

Ce document a été généré automatiquement le 2 octobre 2020.

Tous droits réservés 
Rémy Boucharlat. « À propos de parayadām et paradis perse : perplexité de l'archéologue et perspectives »

Astrid Nunn 


\section{RÉFÉRENCE}

Rémy Boucharlat. «À propos de parayadām et paradis perse : perplexité de l'archéologue et perspectives » in Céline Redard (éd.). Des Contrées Avestiques à Mahabad, via Bisotun. Etudes offertes en hommage à Pierre Lecoq. Neuchâtel : Recherches et publications, 2016, p. 61-80, (Civilisations du Proche-Orient. Série III. Religions et Culture vol. 2)

Cet article a paru dans un volume édité en hommage à l'historien et au philologue Pierre Lecoq. Par le biais du "paradis" l'A. a trouvé une passerelle parfaite entre l'histoire et l'archéologie. En effet le mot vieux perse paradayadām dont est issu "paradis" n'est attesté que dans une seule inscription d'Artaxerxès II à Suse. D'autres lectures et langues paridaidā, partetaš et finalement paradeisos ne résolvent pas le problème du contenu exact de ce mot : jardin plaisant, verger, jardin zoologique, parc pour la chasse ... ? L'A. aborde la question par les données archéologiques. Le "paradis" est un espace défini par une limite matérialisée, un espace vert qui dispose de ressources en eau et un espace aménagé, du moins pour l'irrigation. L'A. réunit les informations actuelles sur les "paradis" de Suse, Pasargades, Persépolis, Karačamirli en Azerbaïdjan et Daskyleion. Le palais de Karačamirli était sans doute entouré d'un vaste espace paysagé. En conclusion, même si les paradis deviennent plus concrets sur le terrain, la toute récente "archéologie des jardins" ne permet pas encore de fournir une réponse précise.

\section{AUTEURS}

\section{ASTRID NUNN}

Université de Munich 